\title{
Neoadjuvant anti-tumor vaccination prior to surgery enhances survival
}

Scott A Fisher ${ }^{1,2^{*}+}$, Amanda Cleaver ${ }^{1,2+}$, Devina D Lakhiani ${ }^{1,2}$, Andrea Khong ${ }^{1,2}$, Theresa Connor ${ }^{1}$, Ben Wylie ${ }^{1}$, W Joost Lesterhuis ${ }^{1,2}$, Bruce WS Robinson ${ }^{1,2}$ and Richard A Lake ${ }^{1,2}$

\begin{abstract}
Background: This study was conducted to determine if anti-tumor vaccination administered prior to partial debulking surgery could improve survival using a murine solid tumour model.

Methods: Tumor incidence and survival rates were compared in mice bearing subcutaneous AB1-HA mesothelioma tumors that received either sham surgery, debulking surgery or vaccination prior to debulking surgery. Additionally, mice were depleted of CD4 and/or CD8 T lymphocytes during vaccination to assess their involvement in vaccine induced anti-tumor immunity. Flow cytometry was performed to characterise changes in the proportion and activation status of immune cells associated with anti-tumor immunity.

Results: Neoadjuvant vaccination combined with debulking surgery resulted in decreased tumor burden, increased survival and generation of tumor-specific immunity compared to surgery alone. Depletion of CD8 T cells completely abrogated any vaccine induced anti-tumor immune response. Conversely, CD4 depletion enhanced CD8 T cell activation resulting in complete tumor regression in $70 \%$ of mice treated with combined surgery and vaccination therapy. Tumor free survival was associated with established immunological memory as defined by the induction of effector memory T cells and resistance to rechallenge with parental AB1 mesothelioma cells.

Conclusions: Neoadjuvant anti-cancer vaccination combined with partial debulking surgery induced CD8-dependent anti-tumor immunity that significantly delayed tumor outgrowth relative to surgery alone. Complete tumor eradication was observed when vaccination and surgery were performed in CD4 T cell depleted animals. This demonstrates that adjuvant immunotherapy can improve post-surgical survival following cancer debulking surgery and provides a scientific rational for clinical trials of such an approach.
\end{abstract}

Keywords: Surgery, Cancer vaccine, Lymphocytes, Cancer immunotherapy, Neoadjuvant

\section{Background}

Surgery is a widely used therapy for many common solid tumors, including thoracic malignancies such as nonsmall cell lung cancer and in some patients with malignant mesothelioma [1,2]. However, surgery alone is often not curative, as these cancers commonly relapse due to local recurrence of unresectable tumor or growth of distant metastases. While adjuvant chemotherapy or

\footnotetext{
*Correspondence: scott.fisher@uwa.edu.au

${ }^{\dagger}$ Equal contributors

${ }^{1}$ School of Medicine \& Pharmacology, University of Western Australia, Perth, 4th Floor, G Block, Queen Elizabeth II Medical Centre, Perth, WA 6009,

Australia

${ }^{2}$ National Research Centre for Asbestos Related Diseases, Harry Perkins

Institute of Medical Research, QQ Block, 6 Verdun Street, Nedlands, WA 6009, Australia
}

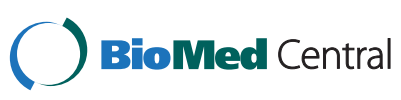

(c) 2014 Fisher et al.; licensee BioMed Central Ltd. This is an Open Access article distributed under the terms of the Creative Commons Attribution License (http://creativecommons.org/licenses/by/4.0), which permits unrestricted use, distribution, and reproduction in any medium, provided the original work is properly credited. The Creative Commons Public Domain Dedication waiver (http://creativecommons.org/publicdomain/zero/1.0/) applies to the data made available in this article, unless otherwise stated. radiotherapy is often used post-surgery to eradicate subclinical distant metastases or residual local disease, these therapies result in limited survival benefits [3-6]; highlighting the need for the development of better adjuvant therapies.

In the last decade there has been considerable improvement in our understanding of the interaction between the host immune system and developing tumor. This has encouraged many researchers to revisit the use of adjuvant immunotherapies to target residual tumor mass. We have previously demonstrated delayed tumor development after combining debulking surgery with antitumor immunotherapy [7-9] and successfully used autologous tumor lysate as an effective anti-cancer vaccine $[10,11]$. Vaccination against known tumor antigens also

ras otherwise stated. 
represents an appealing therapeutic option for the eradication of residual tumor following debulking surgery with different tumor vaccine protocols showing promise in a variety of preclinical models [12-15] and cancer vaccines continue to be clinically evaluated for a range of solid cancers (reviewed in [16-18]).

However, understanding when to vaccinate in relation to surgery may have a significant impact on the outcome of the treatment. In a murine model of melanoma, neoadjuvant vaccination (i.e. prior to surgery) was shown to provide superior protection against post-surgical tumour relapse compared to adjuvant vaccination [13]. The authors assessed the presence and frequency of the key cell types associated with effective anti-tumor immunity (namely CD8 and CD4 T lymphocytes) and found that neoadjuvant vaccination enables surgery to coincide with the peak of the vaccine induced immune response, resulting in increased frequency tumorspecific CD8 T cells present in the tumor, lymph nodes and resection area. In this study we have chosen murine mesothelioma as the model because the tumors mimic their human counterparts molecularly, biologically and clinically and their immunological engagement with the host before and after surgery has been well defined [7-9]. Importantly, they appear to be sensitive to immunotherapy and, as some patients undergo debulking surgery, an ideal situation exists for possible translation to clinical studies.

\section{Methods}

\section{Reagents and mice}

All reagents were purchased from Sigma Aldrich (Castle Hill, NSW. Australia) unless stated otherwise. Female BALB/C $\left(\mathrm{H}-2 \mathrm{~K}^{\mathrm{d}}\right)$ aged between 6 and 8 weeks were obtained from the Animal Resources Centre (Murdoch, Western Australia). All mice were maintained under standard specific pathogen free (SPF) housing conditions and all animal experiments were carried out according to protocols approved by the University of Western Australia Animal Ethics Committee.

\section{Mouse model: tumor inoculation and surgical resection of tumors}

Mice were inoculated subcutaneously (s.c.) with $5 \times 10^{5}$ AB1-HA cells in a total volume of $100 \mu \mathrm{l}$ PBS on the right hand flank unless otherwise stated. For all experiments mice were randomised into groups of 5 once tumors were established (approximately 50-70 $\mathrm{mm}^{2}$ ). Mice were culled when tumors reached the maximum allowable size of $100 \mathrm{~mm}^{2}$ as per UWA AEC approvals. All surgical resections were performed under general anaesthetic using inhalant isoflurane. As a control for the surgical process sham surgery was performed by making incisions into the tumor mass and re-suturing, without debulking. Debulking surgery was performed via elliptic incisions, centred over the s.c. tumors. Skin flaps were elevated to expose adherent tumors. Once tumors were dissected clear of adjacent fascia, $75 \%$ of the tumor mass was removed, with preservation of the tumor pedicles to ensure blood supply (as previously described [19]). Wounds were closed using 4-0 vicryl (polyglactin 910, Ethicon, Australia) continuous sutures. Mice received $0.1 \mathrm{mg} / \mathrm{kg}$ buprenorphine intraperitoneally (i.p.) in the recovery phase for postoperative analgesia as required.

\section{Cell lines \& vaccines}

The murine mesothelioma cell line (AB1) was generated by injecting crocidolite asbestos i.p. into BALB/C mice as previously described [20] and subsequently transfected with the PR8 influenza virus haemagglutinin (HA) gene to produce AB1-HA [21].

Mouse adapted Influenza virus $(\mathrm{PR} / 8 / 34 / \mathrm{H} 1 \mathrm{~N} 1)$ was a kind gift from Dr Peter Henry (UWA School of Pharmacology, Perth Western Australia). PR8 virus was propagated in the allantoic fluid of 9-day old embryonated chicken eggs (Altona Hatchery, Forrestfield, Australia) at $37^{\circ} \mathrm{C}$ for 3 days and harvested as previously described [22], stored in single use aliquots at $-80^{\circ} \mathrm{C}$ and diluted $1: 100$ to $1: 400$ in sterile PBS prior to intranasal vaccination of mice.

Generation of recombinant Modified Vaccinia Ankara expressing Influenza HA antigen. PR8 Influenza HA from the AB1-HA cell line was cloned via RT-PCR into pCR4 cloning vector using the pZeroBlunt-TOPO cloning kit. PCR primers were designed to introduce a Pme I restriction site and add a 6 HIS-3xSTOP-Asc I sequence to the $5^{\prime}$ and $3^{\prime}$ end of the HA cds respectively. The Pme I/Asc I flanked HA-6HIS insert from pCR4-HA was then cloned into the modified Vaccinia Ankara (MVA) shuttle vector pZWIGR3 [23] to produce pZWIGR3HA. To generate recombinant MVA (rMVA) expressing $\mathrm{HA}$, pZWIGR3-HA was transfected into wild type MVA (wtMVA) infected BHK-21 cells and rMVA-HA positive cells purified via sequential rounds of plaque purification based on expression of the fluorescent reporter Venus. The purity of rMVA-HA stocks was confirmed by the absence of wtMVA and presence of HA via PCR prior to expansion and ultra-purification of rMVA-HA stocks for experimental use. All rMVA-HA vaccinations were via i.p. injection in a total volume of $100 \mu \mathrm{l}$ PBS containing $5 \times 10^{5}$ plaque forming units of virus.

\section{Flow cytometry and antibodies}

Flow cytometry was performed using a BD Canto II. All antibodies are anti-mouse unless otherwise stated. Flow cytometry: $\alpha$ CD3-PE-Cy7 (clone 145-2C11), $\alpha$ CD4PerCP-Cy5.5 (clone GK1.5), $\alpha$ CD8-FITC (clone 53-6.7) 
and $\alpha C D 278(\mathrm{ICOS}$ )-APC (clone C398.4A) all BioLegend, USA; $\alpha C D 8-A P C-e f 780$ (clone 53-6.7), $\alpha$ FoxP3-FITC (clone FJK-16 s), $\alpha \mathrm{IFN} \gamma$-APC (clone XMG1.2), $\alpha \mathrm{CD} 44$ PerCP-Cy5.5 (clone IM7), $\alpha$ CCR7-PE (clone 4B12) and $\alpha C D 62 L-A P C$ (Clone MEL-14) all eBioscience, USA; $\alpha$ Ki67-PE (clone B56) (BD Biosciences, USA) and HADextramer-APC (Immudex USA, LLC. Virginia USA). For depletion experiments, purified $\alpha \mathrm{CD} 4$ (GK1.5) and $\alpha \mathrm{CD} 8$ (YTS.169) antibodies were obtained from Absolutions Pty Ltd (Western Australian Institute for Medical Research, Perth, Western Australia). Antibodies were administered by intravenous (i.v.) injection at a dose of $150 \mu \mathrm{g}$ per mouse on day 1 and then $100 \mu \mathrm{g}$ i.p. per mouse every third day as indicated. T cell subset depletion was confirmed by flow cytometry on peripheral blood samples.

\section{Statistical analysis}

Student's $t$ test was used to measure significance between two individual groups, Log rank analysis was performed on survival curves. All analysis was performed using Graph Pad Prism Software (Graph Pad Software Inc., CA, USA) and a p value $<0.05$ considered significant.

\section{Results}

\section{Neoadjuvant vaccination delays tumor growth following} debulking surgery

We have previously demonstrated that partial, but not complete debulking surgery promotes protective antitumour immunity when combined with adjuvant immunotherapy [7]. This is despite complete resection preventing any relapse of residual tumor growth [19]. We have continued to refine our model of tumor debulking by investigating the effect of removing different amounts of tumor on the rate of residual tumor outgrowth and overall survival (Khong et al., manuscript in preparation) When $75 \%$ of the tumor was debulked we observed that the outgrowth of the residual tumor was relatively slow, while in contrast, removing $50 \%$ or less of the tumor had no effect on tumor outgrowth. We therefore chose a $75 \%$ debulk model for this study as it better represents the many clinical scenarios where debulking surgery is the realistic goral rather than complete resection.

To determine whether the addition of PR8 prime and rMVA-HA boost $(\mathrm{P} / \mathrm{B})$ vaccination directed against the HA-neo tumour antigen (as describe above) could improve the survival benefit associated with debulking surgery, groups of AB1-HA tumor bearing mice were treated with either sham surgery (tumor incised, but not debulked), 75\% debulking surgery, prime boost vaccination or a combination of neoadjuvant vaccination and surgery (Figure 1A). A significant delay in tumor growth $(\mathrm{p}<0.001)$ was observed for surgery combined with vaccination group relative to other treatment groups. (Figure 1B). Groups receiving vaccination (alone or in combination with surgery) had noticeably smaller tumors on the day of surgery and a significantly higher proportion of interferon gamma (IFN- $\gamma$ ) expressing tumor-specific CD8 T cells when compared to non-vaccinated groups one week after vaccination (Figure 1D). However, despite all vaccinated groups demonstrating the presence of a functional tumour-specific CD8 T cell immune response, only the combination of neoadjuvant vaccination and $75 \%$ debulking surgery was associated with significantly delayed tumor growth and increased significant survival benefit $(\mathrm{p}<0.001)$ relative to surgery or vaccination alone (Figure 1B).

\section{CD4 T cell depletion during vaccination results in significant survival benefit following debulking surgery}

We hypothesised that the delay in tumor growth in vaccinated mice resulted from a vaccine induced anti-tumor immune response. To test this, we depleted two known key anti-tumour immune effector cell types, CD4 and CD8 $\mathrm{T}$ lymphocytes, during vaccination and compared the overall survival of each group (Figure 2A). Consistent with our earlier experiments, we observed a delay in tumor growth that was associated with a significant survival benefit $(\mathrm{p}<0.01)$ when neoadjuvant vaccination was combined with $75 \%$ debulking surgery compared to surgery alone; although this was not sufficient to prevent tumor outgrowth. Depletion of CD8 T cells, either alone or in combination with CD4 $\mathrm{T}$ cells, completely abrogated any vaccine induced survival benefit, reducing the survival of CD8-depleted groups to that of the surgery only group (Figure $2 \mathrm{~A}$ ), indicating that $\mathrm{CD} 8 \mathrm{~T}$ cells are essential for an effective anti-tumor immune response. Similarly, CD4 depletion during vaccination prevented any vaccine induce delay in tumor growth prior to surgery. However, in contrast to the combined surgery and vaccine group, in which all mice eventually succumb to tumor, we observed complete tumor eradication in $60 \%$ of CD4 depleted mice following debulking surgery (Figure 2A). Further experiments confirmed that CD4 depletion either prior to surgery, or during vaccination was sufficient to eradicate tumor in $50 \%(5 / 10)$ of treated animals and this could be increased to $70 \%(7 / 10)$ when vaccination was combined with surgery (Figure $2 B$ ), demonstrating that vaccination with $\mathrm{CD} 4$ depletion significantly enhances survival compared to surgery alone. In both sets of experiments all mice survived tumor-free for longer than 60 days post-surgery. In addition, they resisted rechallenge with the parental tumor cell-line that does not express HA (black arrow, Figure 2A \& B), indicating that the vaccine-induced immune response was against shared tumor antigens on the $A B 1$ mesothelioma cells and not solely against the transfected HA antigen. 


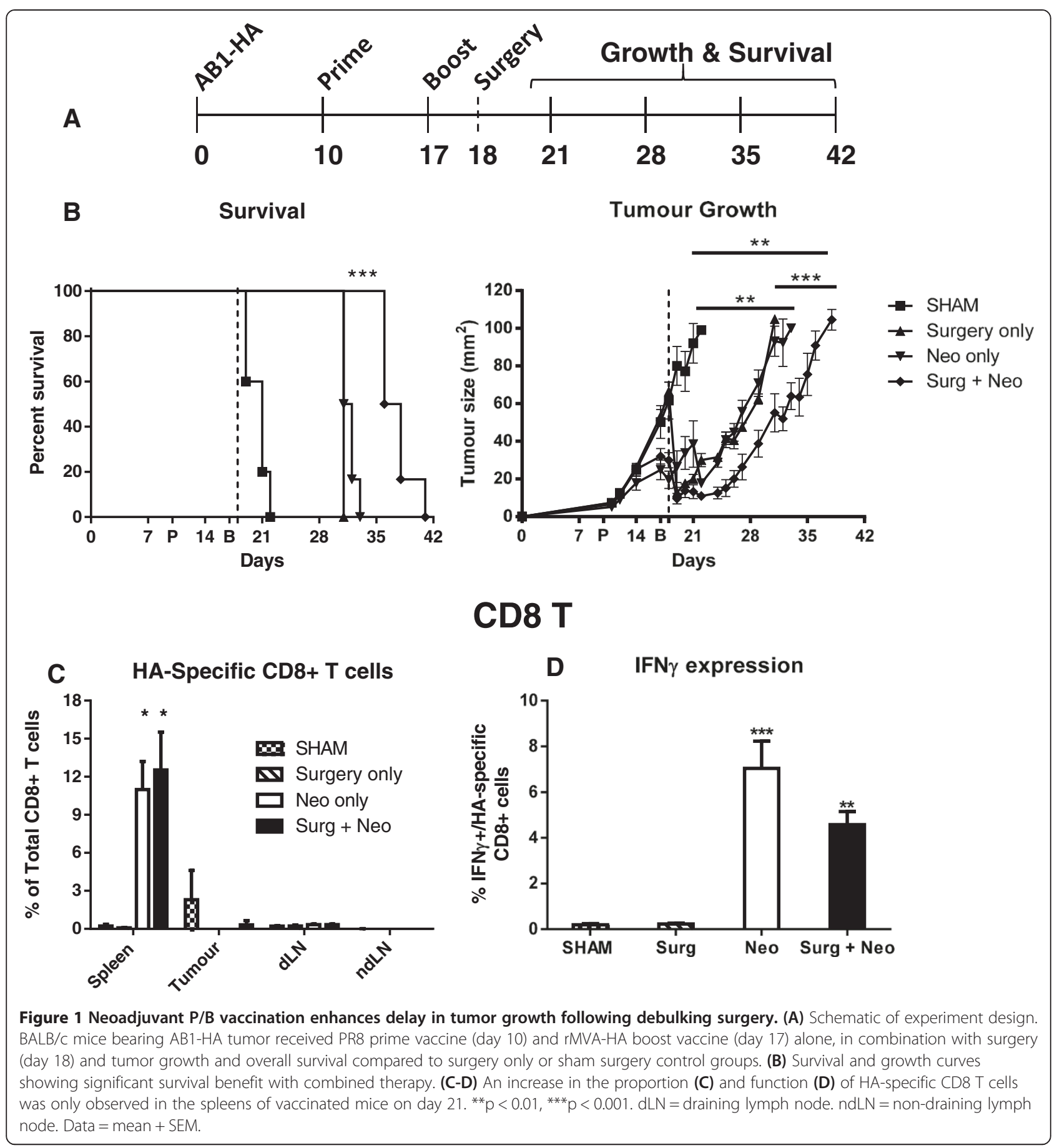

CD4 T cell depletion enhances CD8 T cell activation and establishes immunological protection

Having demonstrated that CD8 T cells were essential for effective anti-tumor immunity, we next assessed the immunological effect of CD4 depletion on CD8 T cells. Peripheral blood taken from mice during CD4 T cell depletion (days 7, 10, 15 and 22, shown in Figure 2B) was analysed by polychromatic flow cytometry to assess the proportion and activation status (ICOS expression) of T cell subsets. The proportion of CD4 and CD8 (as a percentage of total CD3+ lymphocytes) and FoxP3 + CD4+ regulatory $\mathrm{T}$ cells (Treg, as a proportion of total CD4+ T cells) was as expected, the same in all groups at baseline (day 7) and remained unchanged throughout the experiment in all non-CD4 depleted groups (Figure 3). In contrast, the proportion of CD4+ $\mathrm{T}$ cells and Treg were 

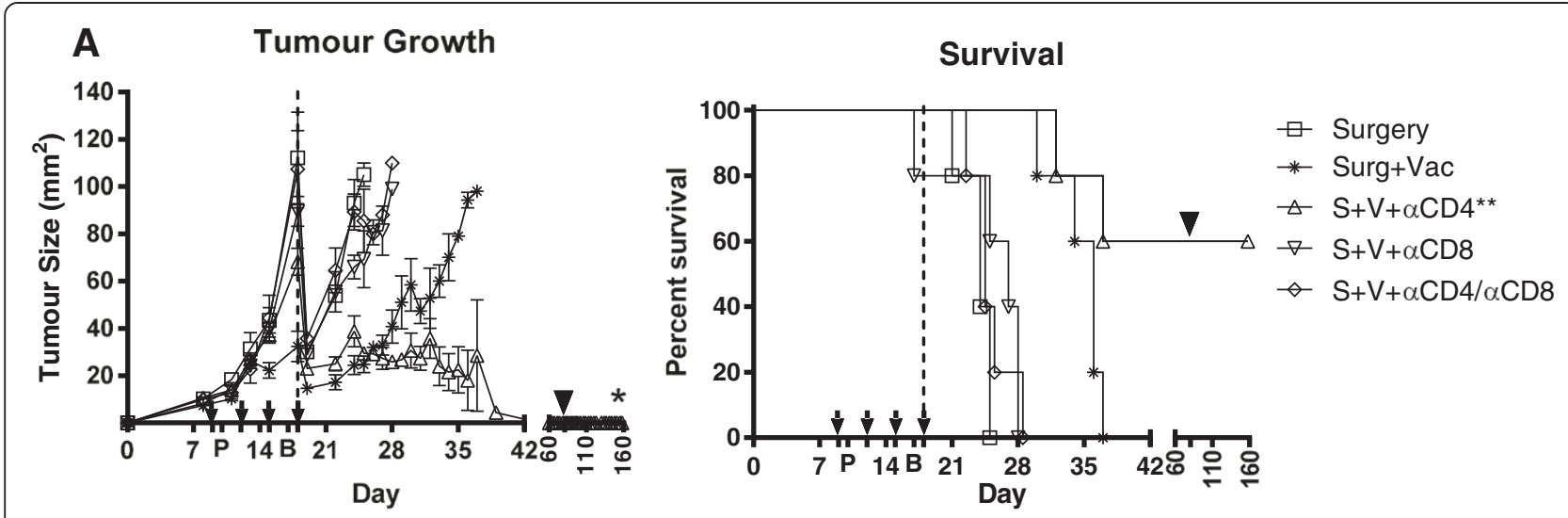

B

Survival

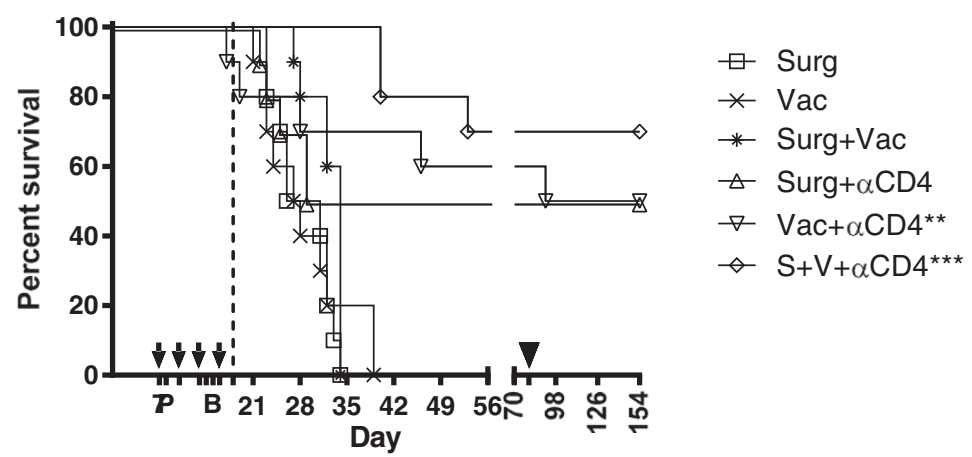

Figure 2 Depletion of CD4 T cells during neoadjuvant vaccination significantly improves survival outcome after debulking surgery. All groups of $A B 1-H A$ bearing BALB/c mice $(n=10)$ received $75 \%$ debulking surgery on day 18 (dotted line). Vaccinated mice received rMVA-HA i.p. 7 days apart (P/B) and depleting antibodies (black arrows) were given every 3 days, starting 1 day prior to the first vaccination ( $(\mathrm{3}$ dx4). Surviving mice were rechallenged on day 81 (black triangle). (A) Tumor growth and survival data showing delay in tumor growth after combined therapy compared to surgery only. Complete tumor regression was only observed when combined therapy was performed in the absence of CD4 T cells (open triangle). (B) Data from repeat experiments showing overall survival following surgery or vaccination as individual or combined therapies, with or without CD4 T cell depletion. Depletion of CD4 T cells significantly improved the survival outcome relative to non-depleted controls. All surviving mice resisted tumor rechallenge. ${ }^{* *} \mathrm{p}<0.01,{ }^{* * *} \mathrm{p}<0.001$. All significant Logrank comparison are to respective untreated controls.

significantly depleted upon anti-CD4 mAb treatment $(\mathrm{p}<0.0001)$, correlating with a significant increase in the proportion and activation status of CD8 T cells (Figure 3C-D, $\mathrm{p}<0.0001$ ). Sustained CD8 T cell activation was observed in CD4 depleted groups, coinciding with tumor regression (days 22-35) and ultimately long term survival (Figure 2B). CD4 T cell depletion was transient and had returned to baseline levels by day 81 when surviving mice were rechallenged with parental tumour (data not shown). Again, all surviving mice resisted rechallenge and remained tumor free until completion of the experiment (day 154). Establishment of immunological memory was consistent with the finding of a significant increase in CD44+ CD62L- effector memory $\mathrm{T}$ cells $\left(\mathrm{T}_{\mathrm{EM}}\right)$ in the spleen and lymph nodes of $\mathrm{CD} 4$ depleted groups at day 140 relative to naïve bearing controls (Figure 4).

\section{Discussion}

Although surgery remains the most effective treatment option for many solid malignancies, regrowth of residual/ non-resectable tumor or growth of distal metastases means that surgery is not always curative, highlighting the need to develop improved, combinatorial treatment strategies. Over the past decade our knowledge of how the immune system recognises and interacts with developing tumor has greatly expanded (reviewed in $[2,24,25]$ ), driving a renewed interest in utilising adjuvant immunotherapies in the treatment of solid tumors. One key question is whether new immunotherapies can add value to tumor debulking surgery.

In this study we assessed the impact of neoadjuvant vaccination in combination with partial debulking surgery. We chose a murine mesothelioma tumour model 


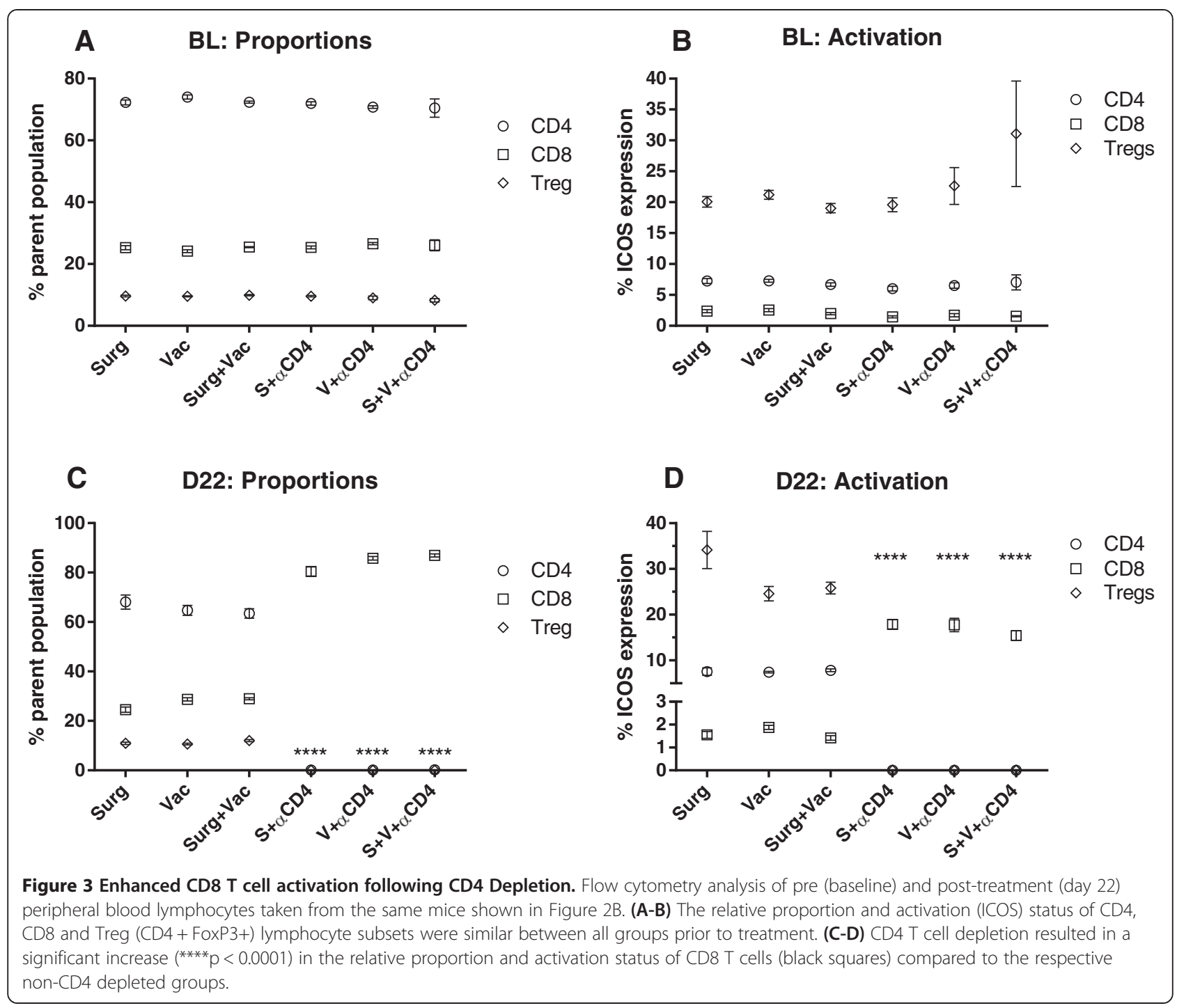

because it mimics its human counterpart and because it represents an ideal tumor for clinical translation. We found that vaccination induced a significant increase in CD8+ cytotoxic T lymphocytes (CTL), a key type of effector cell in anti-tumor immune responses [25]. While surgery or vaccination alone delayed tumor growth relative to controls, a significant survival benefit was only observed when surgery and vaccination were combined. However, unlike Grinshtein et al., who showed that neoadjuvant vaccination protected against tumor regrowth after complete surgical resection [13], we observed that combined treatment could not prevent tumor outgrowth in our model. Instead, complete tumor eradication was only observed when combined vaccination and surgery was performed in the absence of CD4 T cells. While differences between models and vaccination protocols make it hard to directly compare our results, it is known that mesotheliomas secrete immunosuppressive cytokines such as TGF- $\beta$ that may limit vaccine induced anti-tumour immunity in the tumor environment $[26,27]$.

The requirement for CD4 $\mathrm{T}$ cell depletion suggests a role for regulatory $\mathrm{T}$ cells in limiting vaccine induced anti-tumour immunity. Treg are a subset of CD4+ T cells and are recognised as important negative regulators of immune responses [28]. Treg have been shown to promote tumor growth by limiting the efficacy of tumor-specific CD8 $\mathrm{T}$ cell responses and their presence within the tumour infiltrate has been correlated with poor survival prognosis for a number of different malignancies (reviewed in [29]). Therefore, consistent with our findings, vaccination protocols that involve Treg depletion or inhibition of their immunosuppressive function warrant further investigation. 


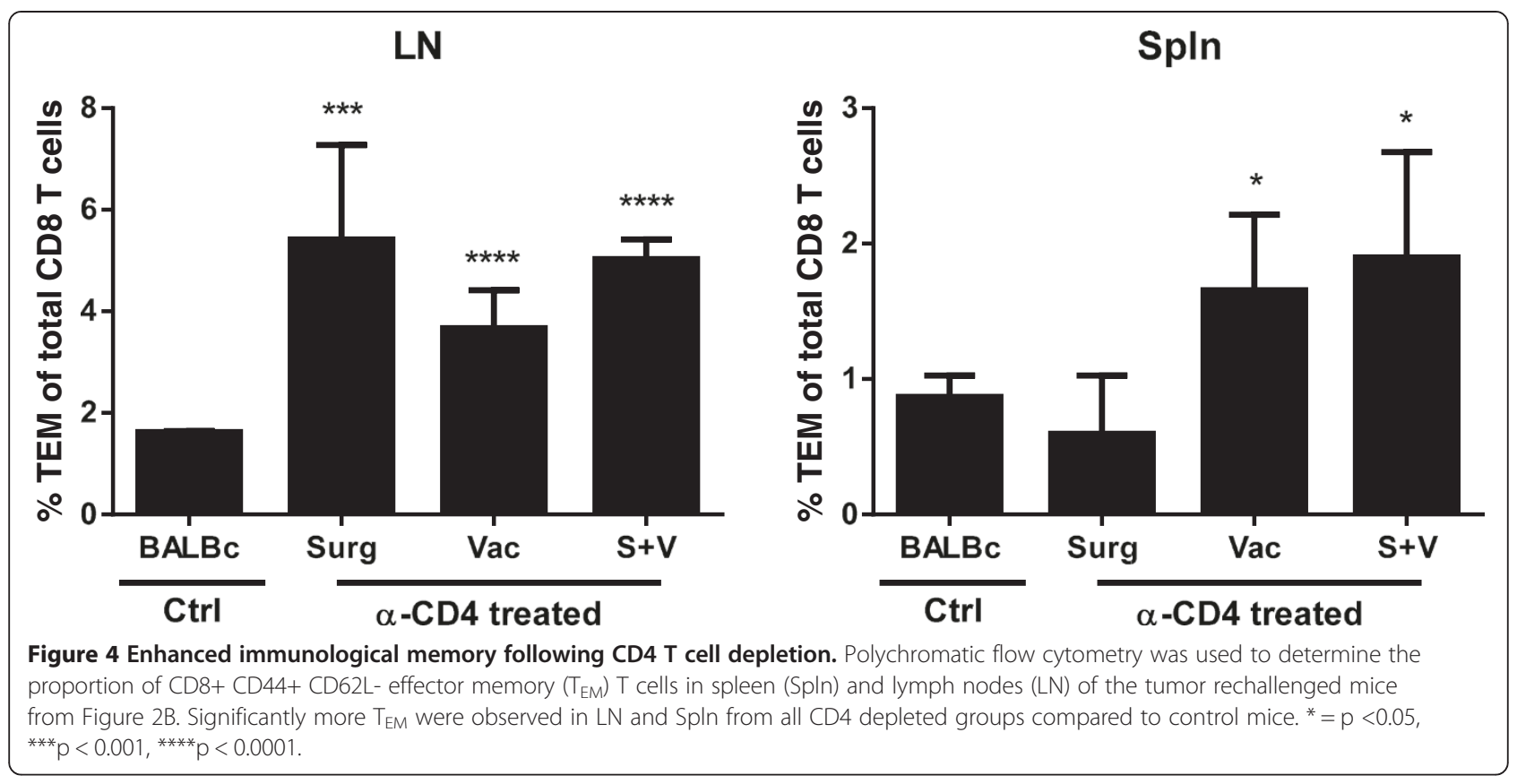

It is important to consider how CD4 depletion might be achieved in a clinical setting. To date cyclophosphamide has been extensively studied for its ability to enhance anti-tumour immunity, including anti-tumour vaccination, by reducing Treg when used at low doses [30-34]. Conversely, high dose cyclophosphamide is lymphodepletive $[35,36]$ and while the use of high dose cyclophosphamide in combination with total body irradiation is critical to increase the effectiveness of adoptive cell therapy (ACT) treatment of melanoma patients $[37,38]$, it is not without associated toxicity and the requirement of $\mathrm{CD} 4$ depletion during $\mathrm{ACT}$ has been questioned [39].

Recent studies have also shown that targeting the surface receptors cytotoxic T-lymphocyte antigen 4 (CTLA-4) and programmed death-1 (PD-1) on both effector and regulatory $\mathrm{T}$ cells, a process known as checkpoint blockade, can dramatically improve anti-tumor immunity [40-44], especially in advanced stage melanoma [45-47]. These new advances in immunotherapy suggest a role for adjuvant immunotherapy to be included in anti-cancer vaccination protocols, particularly when combined with conventional treatments such as debulking surgery.

Taken together, this study demonstrates that neoadjuvant anti-tumor vaccination combined with partial debulking surgery is capable of inducing effective CD8 $\mathrm{T}$ cell dependent anti-tumor immunity. Furthermore, depletion of CD4 $\mathrm{T}$ cells during vaccination produced complete tumor eradication and established immunological memory that could protect against subsequent tumor growth.

\section{Conclusions}

These results suggest that prior to performing debulking surgery, administration of an immunotherapy consisting of transient CD4 $\mathrm{T}$ cell, or more specifically Treg depletion combined with anti-tumor vaccination is an effective therapeutic strategy to enhance survival. These results provide a logical basis for development of adjuvant immunotherapies for patients undergoing cancer surgery in whom complete tumor resection is not likely to be achieved, or who may achieve complete resection, but at high risk or relapse.

\section{Abbreviations}

AB1-HA: Murine mesothelioma cell line; ACT: Adoptive cell transfer; BALB/C: Albino mouse; CTL: Cytotoxic T lymphocyte; CTLA-4: Cytotoxic T lymphocyte antigen 4; FoxP3: Forkhead box transcription factor 3;

HA: Haemagglutinin; ICOS: Inducible T-cell COStimulator; IFN- $\gamma$ : Interferon gamma; i.p.: Intraperitoneal; mAb: Monoclonal antibody; MVA: Modified Vaccinia Ankara; PBS: Phosphate buffered saline; P/B: Prime Boost vaccination; PD-1: Programmed cell death protein 1; PR8: Influenza A PR/8/34 H1N1 Mt Saini strain; s.c.: Subcutaneous; $T_{\text {EM: }}$ T effector memory;

TGF- $\beta$ : Tumour growth factor beta; Treg: Regulatory $\mathrm{T}$ cell.

Competing interests

The authors declare that they have no competing interests.

\section{Authors' contributions}

SF and AC equally contributed to this work and were involved in all aspects from design, data collection, analysis and interpretation and manuscript preparation. DDL, AK, TC and BW contributed to data collection, analysis and interpretation. AK, WJL, BR, and RL contributed to analysis and interpretation and manuscript preparation. All authors read and approved the final manuscript.

\section{Acknowledgements}

The authors acknowledge Professor Don Diamond (Translational Vaccine Research group, Beckman Research Institute City of Hope National Comprehensive Cancer Centre, Duarte CA, 91010, USA) for providing the pZWIGR3 rMVA shuttle vector. The authors would also like to acknowledge 
the facilities, and the scientific and technical assistance of staff at the UWA Animal Care Services and the National Imaging Facility at the Centre for Microscopy, Characterisation \& Analysis, The University of Western Australia, a facility funded by the University, State and Commonwealth Governments. This work was funded by grants from the National Health and Medical Research Council of Australia, Insurance Commission of Western Australia and the Dust Diseases Board of New South Wales. The funding bodies had no role in the study design, data collection and analysis, decision to publish, or preparation of the manuscript.

Received: 13 March 2014 Accepted: 26 August 2014

Published: 4 September 2014

\section{References}

1. Goldstraw P, Ball D, Jett JR, Le Chevalier T, Lim E, Nicholson AG, Shepherd FA: Non-small-cell lung cancer. Lancet 2011, 378:1727-1740.

2. Robinson BW, Lake RA: Advances in malignant mesothelioma. N Engl J Med 2005, 353:1591-1603.

3. Gupta V, Mychalczak B, Krug L, Flores R, Bains M, Rusch VW, Rosenzweig KE: Hemithoracic radiation therapy after pleurectomy/decortication for malignant pleural mesothelioma. Int J Radiat Oncol Biol Phys 2005, 63:1045-1052

4. Rusch WW, Rosenzweig K, Venkatraman E, Leon L, Raben A, Harrison L, Bains MS, Downey RJ, Ginsberg RJ: A phase II trial of surgical resection and adjuvant high-dose hemithoracic radiation for malignant pleural mesothelioma. J Thorac Cardiovasc Surg 2001, 122:788-795.

5. Stevens CW, Forster KM, Smythe WR, Rice D: Radiotherapy for mesothelioma. Hematol Oncol Clin North Am 2005, 19:1099-1115. vii.

6. Zellos $L S$, Sugarbaker DJ: Diffuse malignant mesothelioma of the pleural space and its management. Oncology 2002, 16:907-913. discussion 916-907, 919-920, 925

7. Broomfield S, Currie A, van der Most RG, Brown M, van Bruggen I, Robinson BW, Lake RA: Partial, but not complete, tumor-debulking surgery promotes protective antitumor memory when combined with chemotherapy and adjuvant immunotherapy. Cancer Res 2005, 65:7580-7584

8. Khong A, Brown MD, Vivian JB, Robinson BW, Currie AJ: Agonistic anti-CD40 antibody therapy is effective against postoperative cancer recurrence and metastasis in a murine tumor model. J Immunother 2013, 36:365-372.

9. Mukherjee S, Nelson D, Loh S, van Bruggen I, Palmer L, Leong C, Garlepp MJ, Robinson BW: The immune anti-tumor effects of GM-CSF and B7-1 gene transfection are enhanced by surgical debulking of tumor. Cancer Gene Ther 2001, 8:580-588.

10. Fisher $\mathrm{S}$, Broomfield $\mathrm{S}$, van der Most $\mathrm{R}$, Lake R, Robinson B, Currie A: Heat-shocking of murine malignant mesothelioma cells enhances their effectiveness as an autologous anti-tumour vaccine. J Canc Ther 2012, $3: 47-56$.

11. Jackaman C, Lew AM, Zhan Y, Allan JE, Koloska B, Graham PT, Robinson BW, Nelson DJ: Deliberately provoking local inflammation drives tumors to become their own protective vaccine site. Int Immunol 2008, 20:1467-1479

12. Eslami NS, Shokrgozar MA, Mousavi A, Azadmanesh K, Nomani A, Apostolopoulos V, Day S, Amanzadeh A, Alimohammadian MH: Simultaneous immunisation with a Wilms' tumour 1 epitope and its ubiquitin fusions results in enhanced cell mediated immunity and tumour rejection in C57BL/6 mice. Mol Immunol 2012, 51:325-331.

13. Grinshtein N, Bridle B, Wan Y, Bramson JL: Neoadjuvant vaccination provides superior protection against tumor relapse following surgery compared with adjuvant vaccination. Cancer Res 2009, 69:3979-3985.

14. Mulryan K, Ryan MG, Myers KA, Shaw D, Wang W, Kingsman SM, Stern PL, Carroll MW: Attenuated recombinant vaccinia virus expressing oncofetal antigen (tumor-associated antigen) $5 \mathrm{~T} 4$ induces active therapy of established tumors. Mol Cancer Ther 2002, 1:1129-1137.

15. Vogel TU, Visan L, Ljutic B, Gajewska B, Caterini J, Salha D, Wen T, He L, Parrington M, Cao SX, McNeil B, Sandhu D, Scollard N, Zhang L, Bradley B, Tang M, Lovitt C, Oomen R, Dunn P, Tartaglia J, Berinstein NL: Preclinical qualification of a new multi-antigen candidate vaccine for metastatic melanoma. J Immunother 2010, 33:743-758.

16. Blanchard T, Srivastava PK, Duan F: Vaccines against advanced melanoma. Clin Dermatol 2013, 31:179-190.
17. Koido S, Ohkusa T, Homma S, Namiki Y, Takakura K, Saito K, Ito Z, Kobayashi H, Kajihara M, Uchiyama K, Arihiro S, Arakawa H, Okamoto M, Gong J, Tajiri H: Immunotherapy for colorectal cancer. World I Gastroenterol 2013, 19:8531-8542

18. Thomas A, Hassan R: Immunotherapies for non-small-cell lung cancer and mesothelioma. Lancet Oncol 2012, 13:e301-e310.

19. Brown MD, van der Most R, Vivian JB, Lake RA, Larma I, Robinson BW, Currie AJ: Loss of antigen cross-presentation after complete tumor resection is associated with the generation of protective tumor-specific CD8(+) T-cell immunity. Oncoimmunology 2012, 1:1084-1094.

20. Davis MR, Manning LS, Whitaker D, Garlepp MJ, Robinson BW: Establishment of a murine model of malignant mesothelioma. Int J Cancer 1992, 52:881-886.

21. Marzo AL, Lake RA, Robinson BW, Scott B: T-cell receptor transgenic analysis of tumor-specific CD8 and CD4 responses in the eradication of solid tumors. Cancer Res 1999, 59:1071-1079.

22. Betts RJ, Mann TS, Henry PJ: Inhibitory influence of the hexapeptidic sequence SLIGRL on influenza A virus infection in mice. J Pharmacol Exp Ther 2012, 343:725-735.

23. Manuel ER, Wang Z, Li Z, La Rosa C, Zhou W, Diamond DJ: Intergenic region 3 of modified vaccinia ankara is a functional site for insert gene expression and allows for potent antigen-specific immune responses. Virology 2010, 403:155-162.

24. Lake RA, Robinson BW: Immunotherapy and chemotherapy-a practical partnership. Nat Rev Cancer 2005, 5:397-405.

25. Lesterhuis WJ, Haanen JB, Punt CJ: Cancer immunotherapy-revisited. Nat Rev Drug Discov 2011, 10:591-600.

26. Butt $A Q$, Mills KH: Immunosuppressive networks and checkpoints controlling antitumor immunity and their blockade in the development of cancer immunotherapeutics and vaccines. Oncogene 2013.

27. Jarnicki AG, Lysaght J, Todryk S, Mills KH: Suppression of antitumor immunity by IL-10 and TGF-beta-producing $T$ cells infiltrating the growing tumor: influence of tumor environment on the induction of CD4+ and CD8+ regulatory T cells. J Immunol 2006, 177:896-904.

28. Nishikawa H, Sakaguchi S: Regulatory T cells in cancer immunotherapy. Curr Opin Immunol 2014, 27:1-7.

29. Darrasse-Jeze G, Podsypanina K: How numbers, nature, and immune status of foxp3(+) regulatory T-cells shape the early immunological events in tumor development. Front Immunol 2013, 4:292.

30. Ercolini AM, Ladle BH, Manning EA, Pfannenstiel LW, Armstrong TD, Machiels JP, Bieler JG, Emens LA, Reilly RT, Jaffee EM: Recruitment of latent pools of high-avidity CD8(+) T cells to the antitumor immune response. J Exp Med 2005, 201:1591-1602.

31. Ghiringhelli F, Larmonier N, Schmitt E, Parcellier A, Cathelin D, Garrido C, Chauffert B, Solary E, Bonnotte B, Martin F: CD4 + CD25+ regulatory T cells suppress tumor immunity but are sensitive to cyclophosphamide which allows immunotherapy of established tumors to be curative. Eur J Immunol 2004, 34:336-344.

32. Lutsiak ME, Semnani RT, De Pascalis R, Kashmiri SV, Schlom J, Sabzevari H: Inhibition of CD4(+)25+ T regulatory cell function implicated in enhanced immune response by low-dose cyclophosphamide. Blood 2005, 105:2862-2868.

33. van der Most RG, Currie AJ, Mahendran S, Prosser A, Darabi A, Robinson BW, Nowak AK, Lake RA: Tumor eradication after cyclophosphamide depends on concurrent depletion of regulatory T cells: a role for cycling TNFR2expressing effector-suppressor $\mathrm{T}$ cells in limiting effective chemotherapy. Canc Immunol Immunother 2009, 58:1219-1228.

34. Walter S, Weinschenk T, Stenzl A, Zdrojowy R, Pluzanska A, Szczylik C, Staehler M, Brugger W, Dietrich PY, Mendrzyk R, Hilf N, Schoor O, Fritsche J, Mahr A, Maurer D, Vass V, Trautwein C, Lewandrowski P, Flohr C, Pohla H, Stanczak JJ, Bronte V, Mandruzzato S, Biedermann T, Pawelec G, Derhovanessian E, Yamagishi H, Miki T, Hongo F, Takaha N, et al: Multipeptide immune response to cancer vaccine IMA901 after singledose cyclophosphamide associates with longer patient survival. Nat Med 2012, 18:1254-1261.

35. Ghiringhelli F, Menard C, Puig PE, Ladoire S, Roux S, Martin F, Solary E, Le Cesne A, Zitvogel L, Chauffert B: Metronomic cyclophosphamide regimen selectively depletes $\mathrm{CD} 4+\mathrm{CD} 25+$ regulatory $T$ cells and restores $\mathrm{T}$ and NK effector functions in end stage cancer patients. Canc Immunol Immunother 2007, 56:641-648. 
36. van der Most RG, Currie AJ, Cleaver AL, Salmons J, Nowak AK, Mahendran S, Larma I, Prosser A, Robinson BW, Smyth MJ, Scalzo AA, Degli-Esposti MA, Lake RA: Cyclophosphamide chemotherapy sensitizes tumor cells to TRAlL-dependent CD8 T cell-mediated immune attack resulting in suppression of tumor growth. PLoS One 2009, 4:e6982.

37. Rosenberg SA: Cell transfer immunotherapy for metastatic solid cancer-what clinicians need to know. Nat Rev Clin Oncol 2011, 8:577-585.

38. Rosenberg SA, Yang JC, Sherry RM, Kammula US, Hughes MS, Phan GQ, Citrin DE, Restifo NP, Robbins PF, Wunderlich JR, Morton KE, Laurencot CM, Steinberg SM, White DE, Dudley ME: Durable complete responses in heavily pretreated patients with metastatic melanoma using T-cell transfer immunotherapy. Clin Cancer Res 2011, 17:4550-4557.

39. Dudley ME, Gross CA, Somerville RP, Hong Y, Schaub NP, Rosati SF, White DE, Nathan D, Restifo NP, Steinberg SM, Wunderlich JR, Kammula US, Sherry RM, Yang JC, Phan GQ, Hughes MS, Laurencot CM, Rosenberg SA: Randomized selection design trial evaluating CD8 +-enriched versus unselected tumor-infiltrating lymphocytes for adoptive cell therapy for patients with melanoma. J Clin Oncol 2013, 31:2152-2159.

40. Lesterhuis WJ, Salmons J, Nowak AK, Rozali EN, Khong A, Dick IM, Harken JA, Robinson BW, Lake RA: Synergistic effect of CTLA-4 blockade and cancer chemotherapy in the induction of anti-tumor immunity. PLoS One 2013, 8:e61895.

41. Peggs KS, Quezada SA, Chambers CA, Korman AJ, Allison JP: Blockade of CTLA-4 on both effector and regulatory T cell compartments contributes to the antitumor activity of anti-CTLA-4 antibodies. J Exp Med 2009, 206:1717-1725.

42. Rozali EN, Hato SV, Robinson BW, Lake RA, Lesterhuis WJ: Programmed death ligand 2 in cancer-induced immune suppression. Clin Dev Immunol 2012, 2012:656340

43. Simpson TR, Li F, Montalvo-Ortiz W, Sepulveda MA, Bergerhoff K, Arce F, Roddie C, Henry JY, Yagita H, Wolchok JD, Peggs KS, Ravetch JV, Allison JP, Quezada SA: Fc-dependent depletion of tumor-infiltrating regulatory T cells co-defines the efficacy of anti-CTLA-4 therapy against melanoma. J Exp Med 2013, 210:1695-1710.

44. Topalian SL, Hodi FS, Brahmer JR, Gettinger SN, Smith DC, McDermott DF, Powderly JD, Carvajal RD, Sosman JA, Atkins MB, Leming PD, Spigel DR, Antonia SJ, Horn L, Drake CG, Pardoll DM, Chen L, Sharfman WH, Anders RA, Taube JM, McMiller TL, Xu H, Korman AJ, Jure-Kunkel M, Agrawal S, McDonald D, Kollia GD, Gupta A, Wigginton JM, Sznol M: Safety, activity, and immune correlates of anti-PD-1 antibody in cancer. N Engl J Med 2012, 366:2443-2454.

45. Hodi FS, O'Day SJ, McDermott DF, Weber RW, Sosman JA, Haanen JB, Gonzalez R, Robert C, Schadendorf D, Hassel JC, Akerley W, van den Eertwegh AJ, Lutzky J, Lorigan P, Vaubel JM, Linette GP, Hogg D, Ottensmeier CH, Lebbé C, Peschel C, Quirt I, Clark JI, Wolchok JD, Weber JS, Tian J, Yellin MJ, Nichol GM, Hoos A, Urba WJ: Improved survival with ipilimumab in patients with metastatic melanoma. N Engl J Med 2010, 363:711-723.

46. Robert C, Thomas L, Bondarenko I, O'Day S, DJ M, Garbe C, Lebbe C, Baurain JF, Testori A, Grob JJ, Davidson N, Richards J, Maio M, Hauschild A, Miller WH Jr, Gascon P, Lotem M, Harmankaya K, Ibrahim R, Francis S, Chen TT, Humphrey R, Hoos A, Wolchok JD: Ipilimumab plus dacarbazine for previously untreated metastatic melanoma. N Engl J Med 2011, 364:2517-2526.

47. Weber J: Ipilimumab: controversies in its development, utility and autoimmune adverse events. Cancer Immunol Immunother 2009, 58:823-830.

\section{Submit your next manuscript to BioMed Central and take full advantage of:}

- Convenient online submission

- Thorough peer review

- No space constraints or color figure charges

- Immediate publication on acceptance

- Inclusion in PubMed, CAS, Scopus and Google Scholar

- Research which is freely available for redistribution

Submit your manuscript at www.biomedcentral.com/submit
C Biomed Central 